\title{
PENERAPAN TRAINER INTERFACING MIKROKONTROLER DAN INTERNET OF THINGS BERBASIS ESP32 PADA MATA KULIAH INTERFACING
}

\author{
Hendra Kusumah ${ }^{1}$, Restu Adi Pradana*2 \\ ${ }^{1,2}$ Program Studi Sistem Komputer Universitas Raharja \\ E-mail: ${ }^{1}$ hendra.kusumah@ $\mathrm{raharja.info,*2}$ restu.adi@ raharja.info
}

\begin{abstract}
Abstrak
Ketiadaan alat peraga masih menjadi kendala pada proses pembelajaran mata kuliah interfacing dimana mahasiswa mengalami kesulitan saat memahami materi yang didapatkan selain karena pengalaman praktik mikrokontroler yang kurang membuat mahasiswa kurang memahami bagaimana mengoperasikan mikrokontroler dan juga karena kurangnya pengetahuan dasar mengenai mikrokontroler. Perancangan trainer interface mikrokontroler ini ditujukan sebagai alat peraga untuk membantu memahami interfacing mikrokontroler menggunakan protokol UART, SPI, dan I2C serta dapat digunakan sebagai alat peraga Internet of Things untuk membantu mahasiswa dalam melakukan praktik monitoring dan controlling input output pada mikrokontroler menggunakan smartphone melalui jaringan internet. Dalam merancang trainer ini sebelumnya penulis telah melakukan observasi langsung pada kegiatan pembelajaran di mata kuliah interfacing serta melakukan tanya jawab dengan beberapa mahasiswa. Trainer ini menggunakan modul RFID, RTC dan LCD sebagai alat peraga interfacing yang terhubung dengan mikrokontroler ESP32, serta terdapat komponen berupa LED dan potensiometer untuk mempraktikkan konsep Internet of Things. Pin header untuk GPIO dan ekspansi pin interface mikrokontroler juga tersedia pada trainer ini yang dapat dihubungkan dengan lebih banyak modul dan komponen lain. Modul dan komponen pada rancangan trainer ini dihubungkan dengan mikrokontroler ESP32 dalam satu papan sirkuit terpadu sehingga memberikan kepraktisan dalam menggunakannya.
\end{abstract}

Kata Kunci-Trainer, interfacing, mikrokontroler, ESP32

\begin{abstract}
The absence of props remains a constraint on the learning process interfacing subjects where students have difficulty understanding the material obtained, besides because of the lack of microcontroller practice experience, students don't understand how to operate the microcontroller and also because of the lack of basic knowledge about the microcontroller. The design of the microcontroller interface trainer is intended as a teaching aid to help understand microcontroller interfacing using the UART, SPI, and I2C protocols and can be used as an Internet of Things teaching aid to help students practice monitoring and controlling input output on microcontrollers using smartphones over the internet. In designing this trainer, the author had made direct observations on learning activities in interfacing subjects and conducted questions and answers with several students. This trainer uses RFID, RTC and LCD modules as interfacing props that are connected to the ESP32 microcontroller, and there are components in the form of LEDs and potentiometers to practice the concept of the Internet of Things. The GPIO header pins and microcontroller interface pins expansion are also available on this trainer which can be connected with more modules and other components. Modules and components in the design of this trainer are connected with the ESP32 microcontroller in one
\end{abstract}


integrated circuit board so as to provide practicality in its use.

Keywords - Trainer, interfacing, microcontroller, ESP32

\section{PENDAHULUAN}

Kurangnya media pembelajaran praktikum masih menjadi salah satu alasan terhambatnya materi yang disampaikan dosen untuk dapat dipahami oleh mahasiswa mengakibatkan materi yang didapat hanya sebatas teori saja tanpa memahami praktik untuk penerapannya. Dalam mata kuliah interfacing materi yang diajarkan kepada mahasiswa yaitu mengenai interface pada mikrokontroler dan bagaimana cara mikrokontroler dapat berkomunikasi dengan perangkat atau modul elektronik lainnya dengan menggunakan beberapa protokol interface pada mikrokontroler, namun materi yang disampaikan tidak disertai dengan contoh penerapannya secara langsung pada mikrokontroler dikarenakan belum adanya alat peraga untuk materi interfacing. Hal ini menyebabkan mahasiswa sulit untuk memahami materi bahkan tidak dipahami sama sekali, selain karena kurangnya dasar pengetahuan mahasiswa tentang mikrokontroler, gambaran penerapan dari tujuan mempelajari materi pada mata kuliah interfacing masih belum terilustrasikan dengan baik oleh mahasiswa.

Agar mahasiswa dapat memahami materi dengan baik dan juga memiliki kemampuan untuk menerapkan dan mempraktikkan materi yang didapatkan, maka untuk itu dibutuhkan suatu alat peraga atau trainer interface mikrokontroler untuk dapat membantu mahasiswa dalam memahami materi yang disampaikan dalam mata kuliah interfacing baik secara teori maupun penerapan nya. Alat peraga adalah alat untuk memberikan pelajaran atau yang dapat diamati melalui panca indera. Alat peraga merupakan salah satu dari media pendidikan adalah alat untuk membantu proses belajar mengajar agar proses komunikasi dapat berhasil dengan baik dan efektif [1]. Alat peraga yang dirancang tidak hanya bertujuan untuk mengatasi permasalahan pada proses pembelajaran mata kuliah interfacing, tetapi juga bertujuan untuk memudahkan para mahasiswa yang mengikuti kegiatan ekstrakurikuler kemahasiswaan pada jurusan Sistem Komputer dimana pada kegiatan tersebut terdapat proses pembelajaran dengan materi Internet of Things. Secara umum konsep Internet of Things diartikan sebagai sebuah kemampuan untuk berinteraksi dengan objek lain, lingkungan maupun dengan peralatan komputasi cerdas lain nya melalui jaringan internet [2]. Pada kegiatan itu pula mahasiswa mengalami keterbatasan yang salah satunya yaitu belum adanya alat peraga mikrokontroler yang memiliki fitur untuk dapat terkoneksi dengan internet sehingga mahasiswa belum mampu menerapkan materi yang didapatkan dengan baik.

\section{Bahan yang digunakan \\ Mikrokontroler ESP32}

ESP32 adalah nama dari mikrokontroler yang dirancang oleh perusahaan yang berbasis di Shanghai, China yakni Espressif Systems. ESP32 menawarkan solusi jaringan WiFi yang mandiri sebagai jembatan dari mikrokontroler yang ada ke jaringan WiFi. ESP32 menggunakan prosesor dual core yang berjalan di instruksi Xtensa LX16 [3], ESP32 memiliki spesifikasi seperti yang ditampilkan pada tabel 1 .

Tabel 1 Spesifikasi ESP32

\begin{tabular}{lcc}
\hline No & Atribut & Detail \\
\hline 1 & Tegangan & 3.3 Volt \\
2 & Prosesor & Tensilica L108 32 bit \\
3 & Kecepatan prosesor & Dual 160MHz \\
4 & RAM & $520 \mathrm{~K}$ \\
5 & GPIO & 34
\end{tabular}

Vol 5 No 2 - Agustus 2019 
6

7

8

9

10

11
ADC

Dukungan 802.11

Bluetooth

SPI

I2C
7

$11 \mathrm{~b} / \mathrm{g} / \mathrm{n} / \mathrm{e} / \mathrm{i}$

BLE (Bluetooth Low Energy)

3

2

3

Jika dilihat dari spesifikasi pada tabel maka mikrokontroler ESP32 dapat dijadikan pilihan untuk digunakan pada alat peraga interface mikrokontroler karena mikrokontroler ini memiliki interface yang lengkap, juga memiliki WiFi yang sudah tertanam pada mikrokontroler sehingga tepat untuk digunakan pada alat peraga atau trainer Internet of Things. Pada gambar 1 merupakan pin out dari GPIO pada ESP32.

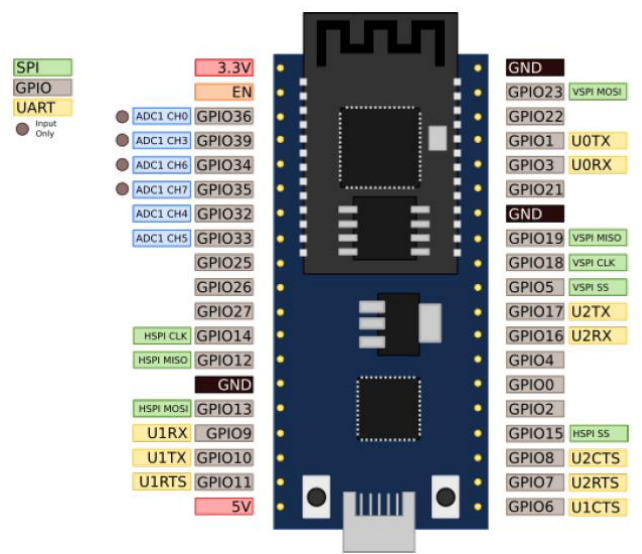

Gambar 1. Pin Out ESP32 [3]

\section{UART (Universal Asynchronous Receiver-Transmitter)}

UART adalah sebuah perangkat di dalam mikrokontroler yang digunakan untuk melakukan komunikasi data serial. Perangkat keras UART dibagi ke dalam tiga bagian/blok besar yaitu transmitter, receiver dan clock (clock generator). Blok transmitter melakukan pengiriman data melalui pin TX. Sedangkan bagian receiver melakukan penerimaan data melalui pin RX. Pada blok clock generator berhubungan dengan setting kecepatan transfer data (baud rate) [4].

\section{SPI (Serial Peripheral Interface)}

SPI adalah standar komunikasi sinkron data serial yang dikenalkan oleh Motorola yang bekerja pada mode full duplex. SPI merupakan high-speed synchronous serial input/output (I/O) port yang memungkinkan untuk pengaturan lebar data yang akan digeser masuk atau keluar dari device dan juga memungkinkan pengaturan pada kecepatan transfer data [5]. Port SPI memiliki empat jalur sinyal yaitu MOSI, MISO, SCK, dan SS.

- MOSI (Master Out Slave In) adalah pin ketika piranti dikonfigurasi sebagai master, maka pin MOSI ini sebagai output, tetapi jika piranti sebagai slave, pin MOSI ini sebagai input.

- MISO (Master In Slave Out) adalah pin ketika piranti dikonfigurasi sebagai master, maka pin MISO ini sebagai input, tetapi jika piranti sebagai slave, pin MISO ini sebagai output

- SCK (Serial Clock) adalah pin ketika piranti dikonfigurasi sebagai master, maka pin SCK ini sebagai output atau pembangkit clock, tetapi jika piranti sebagai slave maka pin SCK sebagai penerima clock dari periferal master.

- SS (Slave Select) adalah pin yang berguna untuk mengkonfigurasi piranti 
mikrokontroler, berfungsi sebagai master atau slave. Jika pin SS diberi logika high maka piranti tersebut dikonfigurasi sebagai master, dan sebaliknya [6].

\section{I2C (Inter-Integrated Circuit)}

I2C adalah protokol interface yang dikembangkan oleh Philips Semiconductor dengan konsep dasar komunikasi dua arah antar IC menggunakan dua kabel. Protokol ini mengizinkan desain sistem untuk saling terkoneksi sampai 128 piranti yang berlainan hanya dengan 2 jalur dua arah, satu untuk serial clock (SCL), dan satunya untuk serial data (SDA) [6]. Setiap piranti yang terhubung dalam I2C memiliki alamat yang unik yang dapat diakses secara perangkat keras dengan protokol master/slave. Setiap piranti slave mempunyai alamat dan piranti master dapat memilih slave mana yang akan menerima data atau men transmitt data.

\section{OLED 128x64}

OLED 128x64 adalah LCD berjenis OLED yang terdiri dari 128 segmen dan 64 common atau 128x64 piksel. Untuk menerima atau mengirim data perintah ke mikrokontroler LCD ini menggunakan interface periferal baik I2C maupun SPI. LCD ini menggunakan driver CMOS bertipe SSD1306 yang menyematkan kontrol kontras, RAM display dan osilator yang mana dapat mengurangi jumlah koneksi eksternal dan konsumsi daya. Driver SSD1306 dirancang untuk panel OLED tipe common cathode. Panel OLED ini juga memiliki fungsi continuous scrolling baik dalam arah vertikal dan horisontal yang memungkinkan untuk menghemat ruang pada layar [7]. LCD ini memiliki 4 buah pin yang dibutuhkan untuk berkomunikasi dengan mikrokontroler menggunakan interface $\mathrm{I} 2 \mathrm{C}$.



Gambar 2. Modul LCD OLED 128x64

\section{RFID MFRC522}

MFRC522 adalah IC reader/writer yang sangat terintegrasi untuk komunikasi contactless di $13.56 \mathrm{MHz}$. Transmitter internal pada MFRC522 mampu mengendalikan antena reader/writer yang dirancang untuk berkomunikasi dengan kartu ISO/IEC 14443 A/MIFARE dan transponder tanpa sirkuit aktif tambahan [8]. Modul RFID in bekerja pada tegangan 3.3 volt dan berkomunikasi dengan mikrokontroler melalui protokol interface SPI yang dapat menangani kecepatan data hingga $10 \mathrm{Mbit} / \mathrm{s}$. Untuk kartu atau tag RFID umumnya bernama PICC yang merupakan singkatan Proximity Integrated Circuit Tag. Kartu ini dapat menyimpan data hingga $1 \mathrm{~K}$ byte dan memiliki range $1 \mathrm{~cm}$ atau $2 \mathrm{~cm}$. 


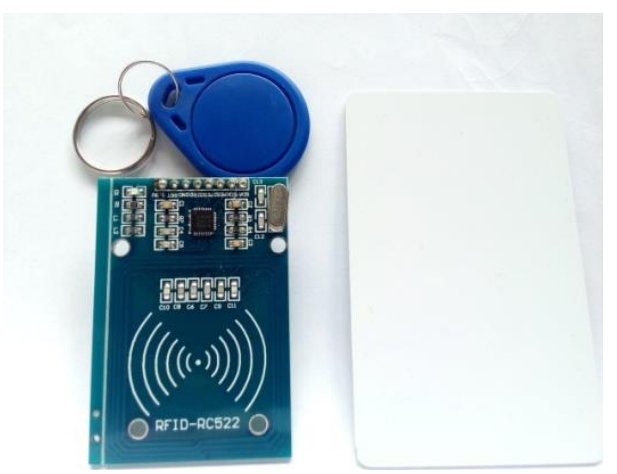

Gambar 3. Modul RFID MFRC522

\section{RTC DS3231}

DS3231 adalah IC real-time clock (RTC) yang terintegrasi dengan sensor temperatur dan kristal. Perangkat ini menggunakan baterai input dan menjaga ketepatan waktu yang akurat ketika daya utama perangkat terganggu. Integrasi resonator kristal meningkatkan akurasi perangkat dalam jangka panjang. Modul RTC DS3231 yang biasa dijumpai sudah disertai dengan baterai 3V CR2032 yang berfungsi sebagai baterai backup agar jika sumber daya utama terganggu maka IC ini tetap menyimpan waktu. IC ini berkomunikasi dengan mikrokontroler melalui protokol interface I2C. Adapun spesifikasi dari modul timer RTC DS3231 adalah sebagai berikut:

- Dapat menyimpan data-data Detik, Menit, Jam, Tanggal, Bulan, Hari dalam Seminggu, dan Tahun, dengan tahun valid hingga 2100

- Sensor Temperatur Digital dengan keakuratan output: $\pm 3{ }^{\circ} \mathrm{C}$

- Dilengkapi baterai backup 3V

- Tegangan operasi: $3.3-5.55 \mathrm{~V}$

- Antarmuka bus I2C, kecepatan transmisi maksimal 400KHz (tegangan kerja 5V)

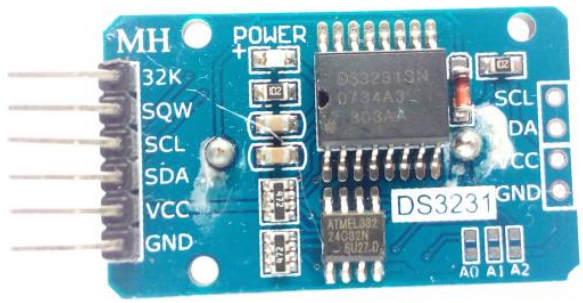

Gambar 4. Modul RTC DS3231

\section{Blynk}

Blynk adalah sebuah platform aplikasi di iOS dan Android untuk mengendalikan Arduino, Raspberry Pi, dan sejenis nya melalui internet. Blynk juga merupakan sebuah dasbor digital dimana dapat membangun sebuah antarmuka grafis untuk sebuah alat yang dibuat hanya dengan "drag and drop" widget. Blynk di desain untuk Internet of Things yang dapat mengendalikan hardware dari jarak jauh, blynk juga dapat menampilkan data sensor, menyimpan data, dan memvisualisasikan nya, serta masih banyak hal lainya yang dapat dilakukan oleh blynk [9]. Ada tiga komponen utama dalam platform ini, yaitu Blynk App, Blynk Server, dan Blynk Library. Blynk App adalah aplikasi Blynk yang ada pada platform Android atau iOS di smartphone untuk dapat membuat sebuah antarmuka dari alat yang dibuat dengan menggunakan berbagai widget yang disediakan. Lalu Blynk Server adalah sebuah server Blynk yang bertanggung jawab atas semua komunikasi antara aplikasi Blynk pada smartphone dengan hardware atau alat yang dibuat. Sedangkan Blynk Library adalah sebuah library yang 
memberi kemampuan hardware atau alat yang dibuat untuk dapat berkomunikasi dengan Blynk server dan memproses semua data dari input output.

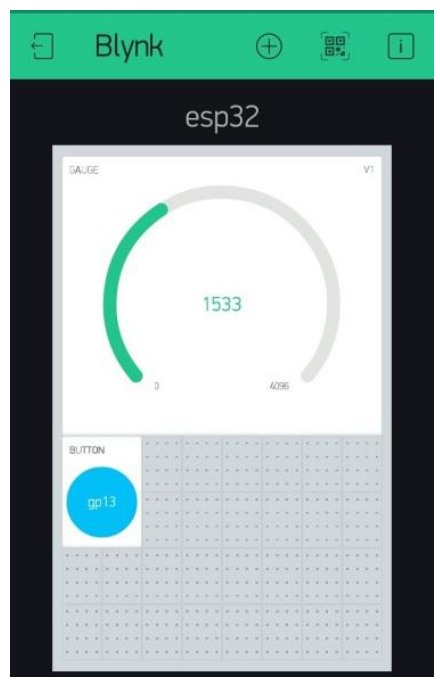

Gambar 5. Aplikasi Blynk

\section{METODE PENELITIAN}

Saat melakukan eksperimen perancangan trainer interface mikrokontroler, sebelumnya telah dilakukan observasi dengan turut mengikuti pembelajaran pada mata kuliah interfacing serta mewawancarai beberapa mahasiswa yang mengikuti kegiatan tersebut untuk mengetahui kendala yang dialami dalam memahami materi. Kemudian data hasil observasi selanjutnya di analisis tentang bagaimana cara memecahkan kendala yang dialami mahasiswa berdasarkan opini dari beberapa mahasiswa saat diwawancara. Dari hasil analisis tersebut dapat disimpulkan bahwa kendala tersebut bisa diminimalisir dengan adanya alat peraga atau trainer pada kegiatan pembelajaran.

\section{Perancangan Hardware}

Untuk merancang trainer interface mikrokontroler maka trainer ini harus memiliki beberapa modul elektronik yang terkoneksi dengan mikrokontroler melalui beberapa protokol interface pada mikrokontroler seperti UART (Universal Asynchronous Receiver-Transmitter), SPI (Serial Peripheral Interface), I2C (Inter-Integrated Circuit), dan sebagainya. Alat peraga yang dirancang menggunakan tiga jenis modul elektronik dalam satu papan sirkuit terpadu yang dapat berkomunikasi dengan mikrokontroler yaitu LCD OLED 128x64 I2C 0.9 inch sebagai output, kemudian modul RFID MFRC522 yang berkomunikasi menggunakan protokol interface SPI, serta modul Real Time Clock DS3231 dengan protokol interface I2C. Mikrokontroler yang dipakai pada rancangan alat peraga ini juga memiliki kemampuan yang dapat terhubung dengan jaringan internet yaitu mikrokontroler ESP32. Mikrokontroler ini sudah memiliki konektivitas WiFi yang tertanam dalam satu chip untuk menjalankan berbagai aplikasi Internet of Things bahkan Bluetooth juga sudah tersedia pada chip mikrokontroler ESP32.

Dalam mendesain trainer ini digunakan software Eagle Cadsoft 7.1.0 untuk menggambar skematik rancangan trainer dan mendesain PCB nya dengan menggunakan library tambahan untuk tampilan komponen modul yang terhubung dengan mikrokontroler. 


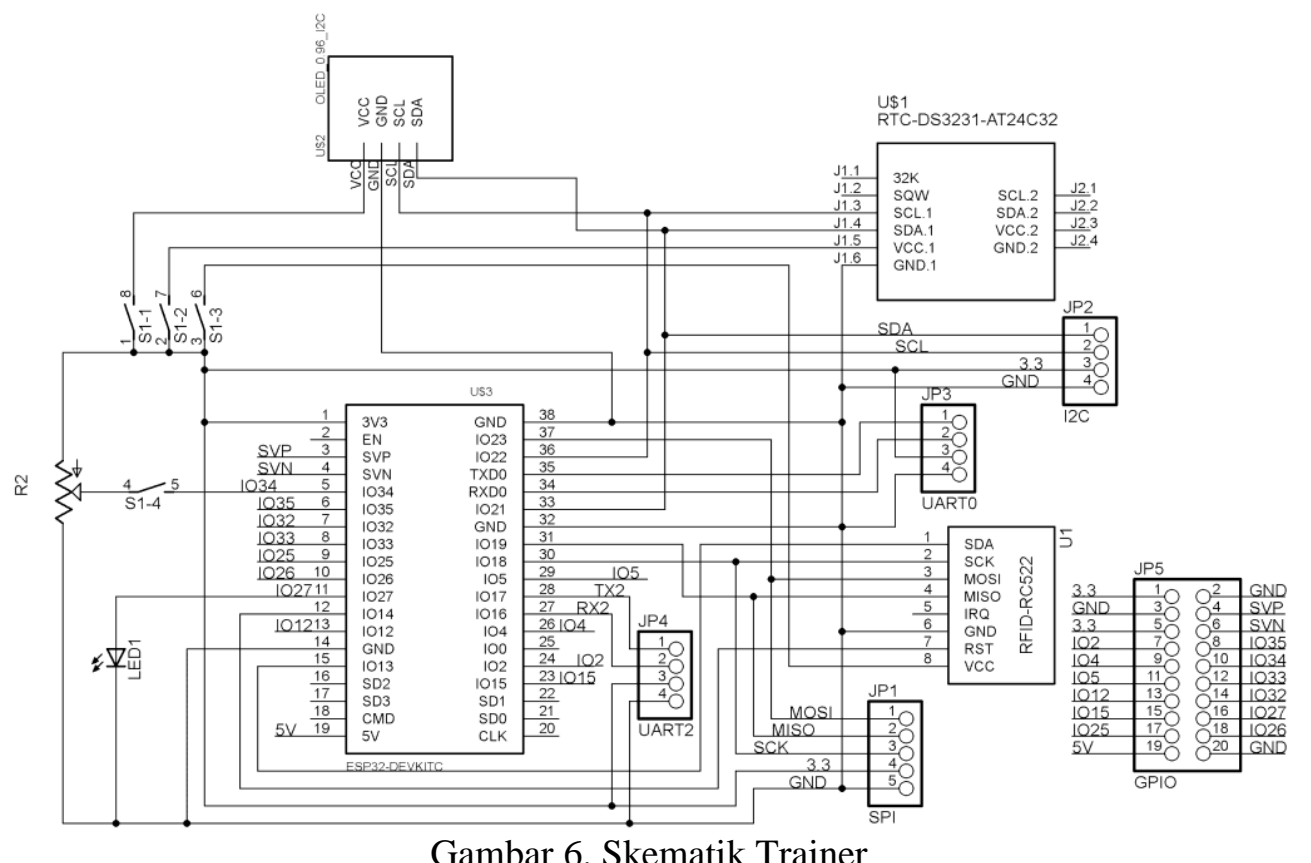

Skematik yang dibuat juga dapat digunakan sebagai acuan dalam membuat prototype trainer interface mikrokontroler sebelum rancangan dirangkai dengan PCB. Prototype trainer ini dibuat dengan menghubungkan semua komponen yang dibutuhkan kedalam breadboard seperti pada diagram blok pada gambar 7 .

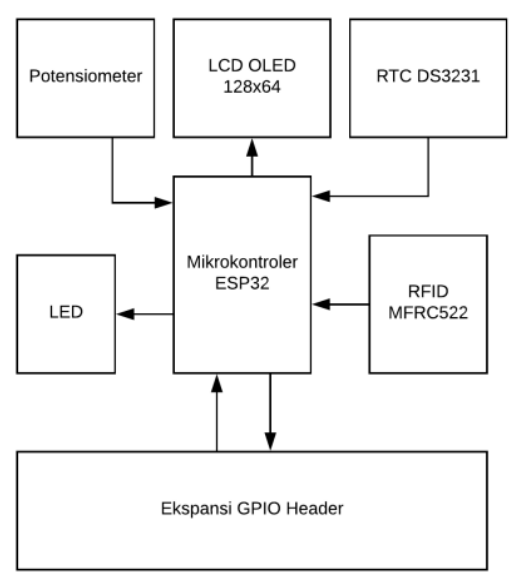

Gambar 7. Diagram Blok Trainer Interface Mikrokontroler

Untuk rangkaian LCD OLED 128x64 dan RTC DS3231 dihubungkan ke pin I2C pada ESP32 yaitu pin GPIO 21 untuk SDA dan pin GPIO 23 untuk SCL. Sedangkan untuk rangkaian RFID MFRC522 dihubungkan dengan pin SPI pada ESP32 yaitu GPIO23 untuk MOSI, GPIO19 untuk MISO, GPIO18 untuk SCK, GPIO13 untuk SS, dan pin GPIO14 untuk reset. Rangkaian trainer ini tidak terbatas hanya dengan menggunakan ketiga modul yang digunakan sebagai alat peraga interface mikrokontroler, namun dapat menggunakan modul elektronik lainnya yang menggunakan interface I2C, SPI, dan UART dengan menghubungkannya ke pin header ekspansi interface pada trainer ini seperti pada gambar desain PCB. 


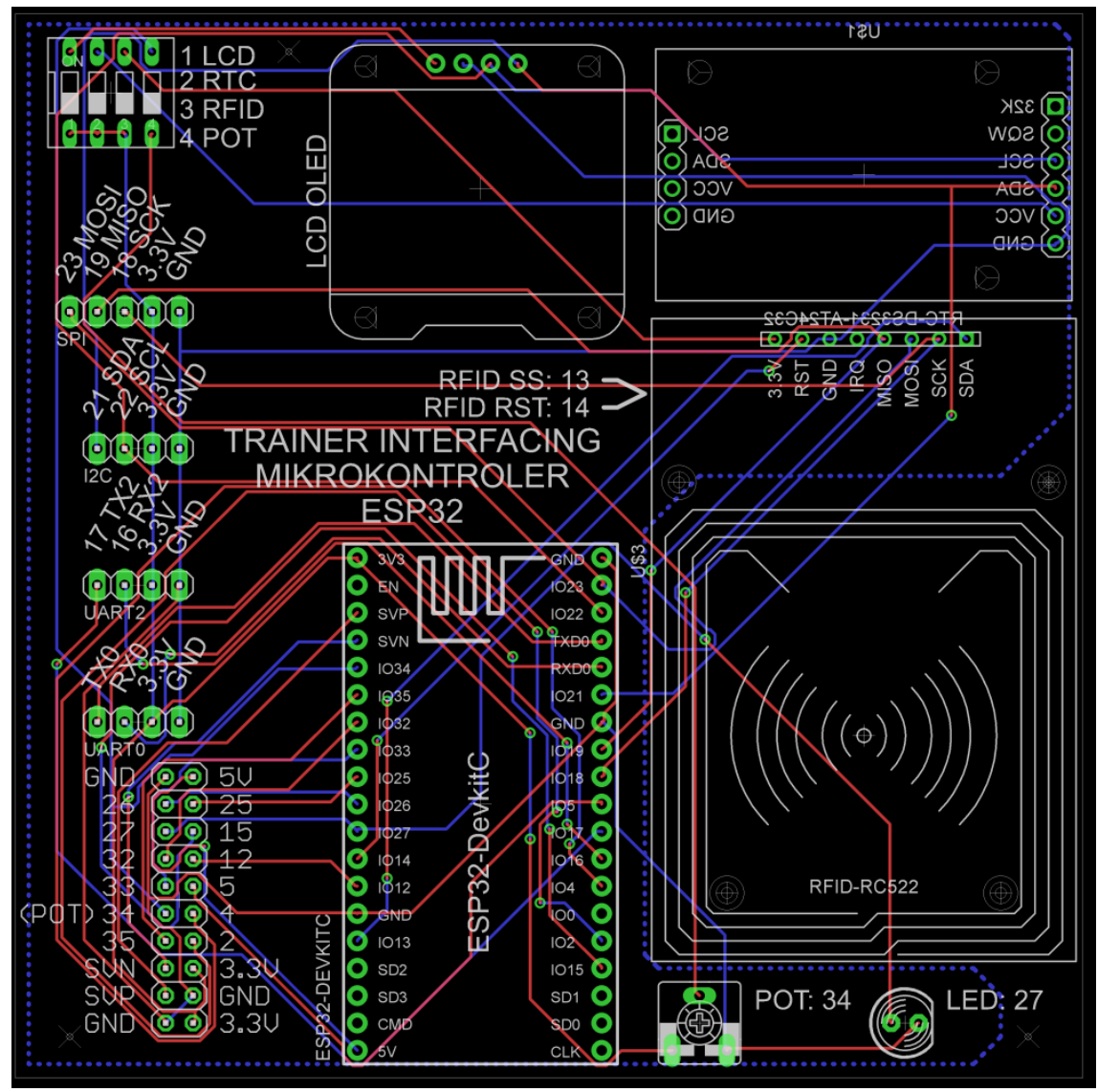

Gambar 8. Desain PCB Trainer Interface Mikrokontroler

Terdapat beberapa komponen yang ada pada desain PCB selain ketiga modul yang dijadikan alat peraga interfacing, yaitu satu buah LED sebagai output yang terhubung ke GPIO27 pada ESP32, kemudian potensiometer yang terhubung dengan pin GPIO34 pada ESP32 yang berfungsi sebagai analog input, 4 buah pin header yang masing masing berfungsi sebagai ekspansi pin interface ESP32 yaitu ekspansi untuk pin SPI, I2C, UART0, dan UART2. Header ekspansi pin interface ini digunakan jika dalam praktiknya trainer ini menggunakan modul elektronik tambahan yang menggunakan interface I2C, SPI, dan UART selain modul yang sudah tertanam pada trainer. Serta terdapat DIP Switch 4 Pin untuk menyalakan dan mematikan beberapa komponen input output pada trainer ini. Pada DIP switch ini terdapat 4 toggle switch yang bernomor, pada desain PCB trainer ini untuk toggle switch nomor 1 berfungsi untuk mengaktifkan atau menonaktifkan LCD OLED 128x64, nomor 2 untuk RTC DS3231, nomor 3 untuk modul RFID MFRC522, nomor 4 untuk potensiometer.

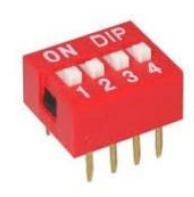

Gambar 9. DIP Switch 4 Pin 


\section{Perancangan Software}

Agar trainer ini dapat difungsikan sebagai alat peraga dalam mempelajari Internet of Things maka perlu adanya platform untuk menjalankan aplikasi Internet of Things yaitu platform Blynk. Aplikasi Blynk perlu di install di perangkat Android atau iOS agar dapat berkomunikasi dengan hardware yaitu ESP32. Aplikasi blynk berfungsi sebagai tampilan yang berupa button atau slider sebagai input pada ESP32 yang terhubung dengan jaringan, dan juga tampilan berupa grafik, gauge, dan labeled display sebagai penampil output data dari ESP32. Cara kerja blynk yaitu setiap kali menekan Button pada widget di aplikasi blynk, maka blynk app akan mengirimkan pesan yang akan masuk ke Blynk Server, dimana pesan tersebut akan menemukan jalanya menuju hardware atau alat yang dibuat, begitu pula sebaliknya.

Untuk memprogram ESP32 digunakan software Arduino IDE untuk melakukan kompilasi dan upload program atau sketch kedalam mikrokontroler ESP32. Pada dasarnya Arduino IDE adalah software khusus untuk memprogram berbagai jenis board Arduino, dan secara default belum kompatibel dengan mikrokontroler ESP32. Agar Arduino IDE dapat digunakan untuk memprogram ESP32 maka perlu menginstall board library ESP32 pada Arduino IDE. Aplikasi blynk dan modul yang tertanam pada trainer ini juga memerlukan library tambahan agar program dapat dikenali oleh Arduino IDE, seperti library blynk, LCD, MFRC522, dan RTC. Arduino IDE juga memiliki fitur bernama serial monitor yang berfungsi untuk mengirim dan menerima pesan dari komputer ke mikrokontroler atau sebaliknya melalui USB.

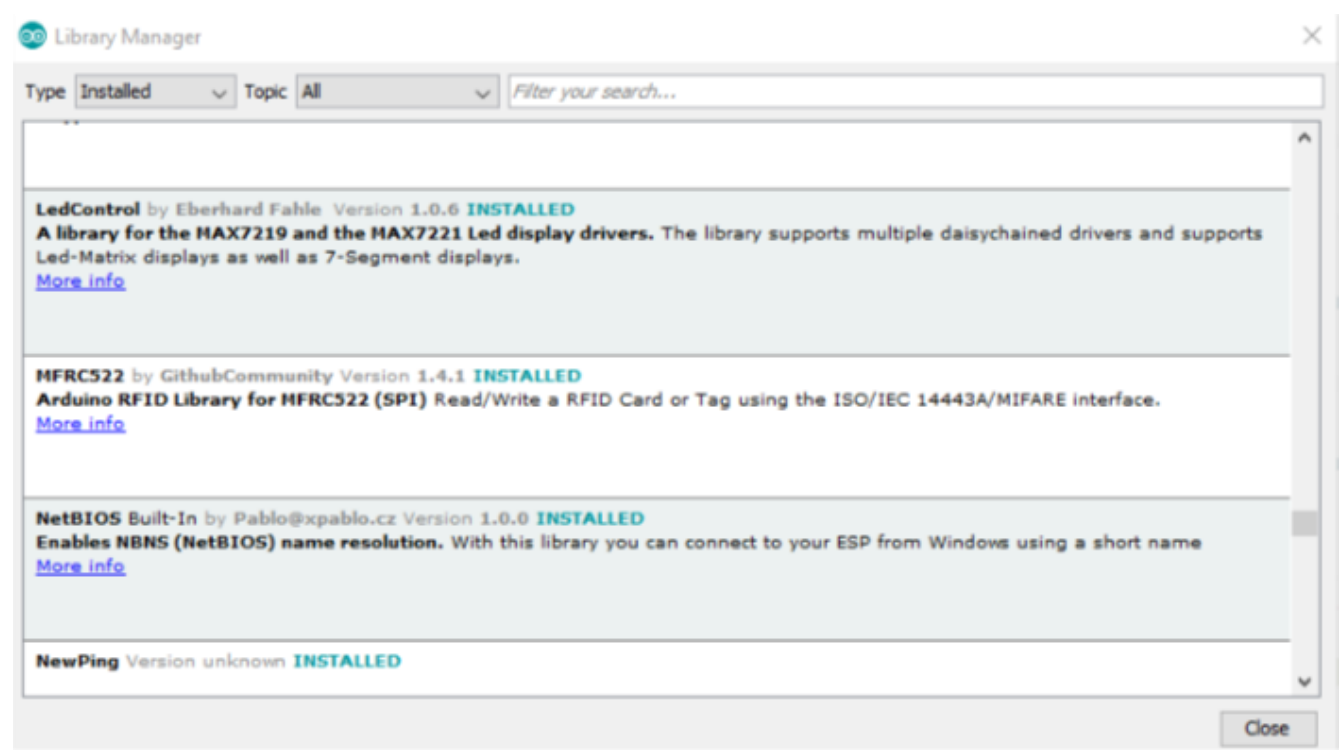

Gambar 10. Library Manager pada Arduino IDE

\section{Literature Review}

Literature review ini dilakukan oleh penelitian dalam upaya melengkapi dan kedepannya. Adapun Literature Review sebagai landasan dalam mendukung penelitian adalah sebagai berikut:

1. Penelitian yang dilakukan oleh Yoyo Somantri pada tahun 2016 yang berjudul "Pengembangan Microcontroller Embedded System untuk Training Kits". Penelitian ini membahas tentang hasil pengembangan training kit mikrokontroler, trainer mikrokontroler ini menggunakan dua buah mikrokontroler berjenis ATmega 16/32 
sebagai master dan AT89S51/52 sebagai target. Training kit ini tidak menggunakan bantuan PC pada proses pemrograman nya, melainkan menggunakan mikrokontroler master untuk menuliskan kode mnemonic dan menerjemahkan kode mnemonik menjadi kode mesin yang di upload ke mikrokontroler target. Kode mnemonik ini dituliskan oleh user melalui keyboard PC bersoket PS2 yang hasilnya ditampilkan pada LCD. Output pada trainer mikrokontroler embedded system ini berupa led, relay, seven segment, LCD, dan motor stepper. Sedangkan input menggunakan keypad, ultrasonic sensor, dan push button.

2. Penelitian yang dilakukan oleh Julham dan Hikmah Adwin Adam pada tahun 2018 yang berjudul "Perancangan dan Pembuatan Trainer Komunikasi RS232 Menggunakan Komputer dan Mikrokontroler". Pada penelitian ini pembuatan trainer dirancang untuk untuk meningkatkan pengetahuan mahasiswa dan keterampilan pemrograman komunikasi RS232 pada mata kuliah Interfacing. Mikrokontroler pada trainer ini menggunakan chip ATmega8535 sebagai media percobaan interfacing mikrokontroler dengan komputer beserta komponen input berupa push button dan komponen output berupa led.

3. Penelitian yang dilakukan oleh Sokop, Mamahit, dan Sompie pada tahun 2016 yang berjudul "Trainer Periferal Antarmuka Berbasis Mikrokontroler Arduino Uno". Pada penelitian ini trainer yang dihasilkan menggunakan Arduino UNO sebagai board mikrokontroler berbasis ATmega328 dengan komponen input berupa keypad, push button, LDR, sensor suhu LM35 dan potensiometer. Sedangkan komponen output yang digunakan adalah led, 7 segment, buzzer, lcd, dan motor DC. Trainer ini dirancang untuk membantu mahasiswa teknik elektro dalam menyelesaikan setiap percobaan dalam penerapan materi yang diterima. Setiap komponen pada trainer ini tidak terhubung satu dengan yang lain nya, dalam penggunaanya maka diperlukan kabel jumper sebagai penghubungnya.

4. Penelitian yang dilakukan oleh Fayakun Muchlis, Dwi Sulisworo, dan Moh Toifur pada tahun 2018 yang berjudul "Pengembangan Alat Peraga Fisika Berbasis Internet of Things untuk Praktikum Hukum Newton II". Penelitian ini bertujuan untuk membuat alat peraga Hukum Newton kedua dalam ilmu fisika berbasis Internet of Things. Alat peraga ini terdiri dari bidang datar yang licin dan kasar, sensor photogate, kotak sistem kontrol, kabel audio, dan aplikasi Newton App. Ada lima buah sensor photogate bertindak sebagai detektor yang mendeteksi percepatan benda yang bergerak melintasi gate tersebut. Masing masing sensor photogate terdapat sensor LDR yang terhubung dengan lampu led. Alat peraga ini menggunakan NodeMCU dengan mikrokontroler ESP8266 untuk mengkalkulasi data waktu yang didapatkan dari kelima sensor photogate dan menampilkannya pada LCD dan mengirim data hasil kalkulasi nilai percepatan benda ke website thingspeak.com. Pengguna alat peraga ini dapat mengetahui data nilai percepatan melalui smartphone dengan mengakses NewtonApp.

5. Penelitian yang dilakukan oleh Riza Lukman pada tahun 2017 yang berjudul "Trainer Mikrokontroler Sebagai Media Pembelajaran Sistem Kontrol Untuk Siswa Kelas XI Program Keahlian Teknik Otomasi Industri di SMK Negeri 2 Kendal”. Penelitian ini menghasilkan media pembelajaran berupa trainer mikrokontroler AVR menggunakan ATmega16 dengan 4 modul rangkaian mencakup perangkat input/output yaitu LED, tombol, ADC, seven segment, LCD, matriks LED, komunikasi RS232, PWM, motor servo, dan motor DC. Penelitian ini bertujuan untuk mengembangkan media pembelajaran yang digunakan pada mata pelajaran sistem kontrol terprogram program keahlian Teknik Otomasi Industri di SMK Negeri 2 Kendal. 


\section{HASIL DAN PEMBAHASAN}

Alat trainer ini dibuat dengan merangkai seluruh komponen dan modul elektronik dalam satu papan PCB, dan terdapat DIP switch $4 \mathrm{P}$ untuk mengaktifkan atau menonaktifkan modul LCD, RFID, RTC, dan input potensiometer sesuai kebutuhan penggunaan. Pada trainer ini terdapat beberapa pin header yang berfungsi sebagai ekspansi pin interface mikrokontroler ESP32 dan GPIO (General Purpose Input Output) sebagai pin input output ESP32 yang disertai dengan keterangan pin yang terhubung dari pin header ke ESP32 pada PCB untuk memudahkan pemakai trainer ini dalam memprogram.

Program yang digunakan untuk trainer ini yaitu menggunakan bahasa $\mathrm{C}$ dan compiler Arduino IDE yang telah ditambahkan dukungan untuk board mikrokontroler ESP32. Komputer yang akan memprogram trainer ini harus sudah terinstall software Arduino IDE, driver usb to serial CP2102, dan beberapa library sesuai dengan kebutuhan modul yang akan dihubungkan pada trainer ini. Driver usb to serial CP2102 berfungsi agar komputer dapat mengenali mikrokontroler ESP32 sebagai perangkat yang terhubung pada COM port, karena pada trainer ini menggunakan chip bertipe CP2102 sebagai konverter USB ke UART untuk berkomunikasi antara komputer yang menggunakan interface USB dengan mikrokontroler ESP32 interface UART.

Sebelum digunakan sebagai alat peraga, hasil dari perancangan alat trainer ini harus diuji coba sesuai dengan tujuan perancangan yaitu sebagai alat peraga interface mikrokontroler dan Internet of Things. Pengujian dilakukan dengan cara menguji masing masing fungsi dari modul elektronik yang terhubung dengan mikrokontroler, menguji potensiometer sebagai input dan LED sebagai output.

\section{Interfacing I2C dengan RTC DS3231 dan LCD OLED 128x64}

Untuk menampilkan data jam ke LCD maka library RTClib.h harus di install pada Arduino IDE agar fungsi program untuk menampilkan data waktu hari tanggal bulan tahun dapat digunakan dan library Wire.h, Adafruit_GFX.h, dan Adafruit_SSD1306.h juga harus di include ke dalam list program agar fungsi fungsi dalam pemrograman LCD dapat digunakan serta alamat I2C pada LCD dan RTC juga harus dideklarasikan pada list program karena setiap perangkat I2C harus memiliki alamat. Sebelum memprogram LCD dan RTC pada trainer ini pastikan switch untuk LCD dan RTC diaktifkan dengan cara memindahkan posisi toggle switch ke posisi ON pada toggle nomor 1 untuk LCD dan RTC.

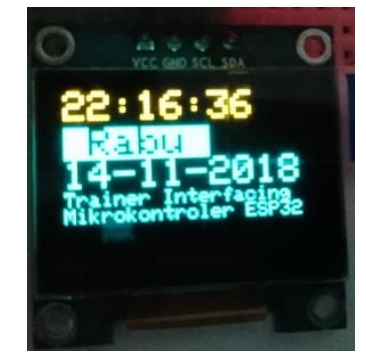

Gambar 11. Percobaan dengan LCD dan RTC

Percobaan ini dilakukan untuk meningkatkan pemahaman secara praktik dalam mengaplikasikan konsep-konsep teori penggunaan I2C sebagai protokol komunikasi data antara mikrokontroler dengan modul yang menggunakan interface I2C. Pengguna trainer ini akan mempraktikan materi interface I2C pada mata kuliah interfacing dengan modul RTC DS3231 dan LCD OLED mulai dari memahami pin mikrokontroler yang digunakan untuk menggunakan protokol interface I2C serta memahami list program untuk melakukan komunikasi antara mikrokontroler dengan modul menggunakan protokol interface I2C. 


\section{Interfacing SPI dengan RFID MFRC522}

Pengujian modul RFID pada trainer ini yaitu dengan percobaan membaca data tag atau kartu RFID yang kemudian data yang dibaca ditampilkan pada serial monitor. Sebelum memprogram RFID pastikan library MFRC522.h sudah di install pada Arduino IDE dan posisi toggle switch nomor 3 pada trainer ini sudah pada posisi ON. Pada saat memprogram library MFRC522.h harus di include beserta library SPI.h ke dalam list program agar fungsi program untuk RFID dan interface SPI dapat digunakan. Modul RFID ini menggunakan interface SPI dalam berkomunikasi dengan mikrokontroler ESP32 maka terdapat pin SS (slave select) dan pin reset yang harus dideklarasikan pada list program. Kedua pin ini sebetulnya dapat dikonfigurasi, namun pada trainer ini kedua pin tersebut sudah terhubung dengan mikrokontroler sesuai dengan desain PCB trainer sehingga tidak dapat dikonfigurasi dan harus mengikuti konfigurasi berdasarkan petunjuk pada trainer ini.

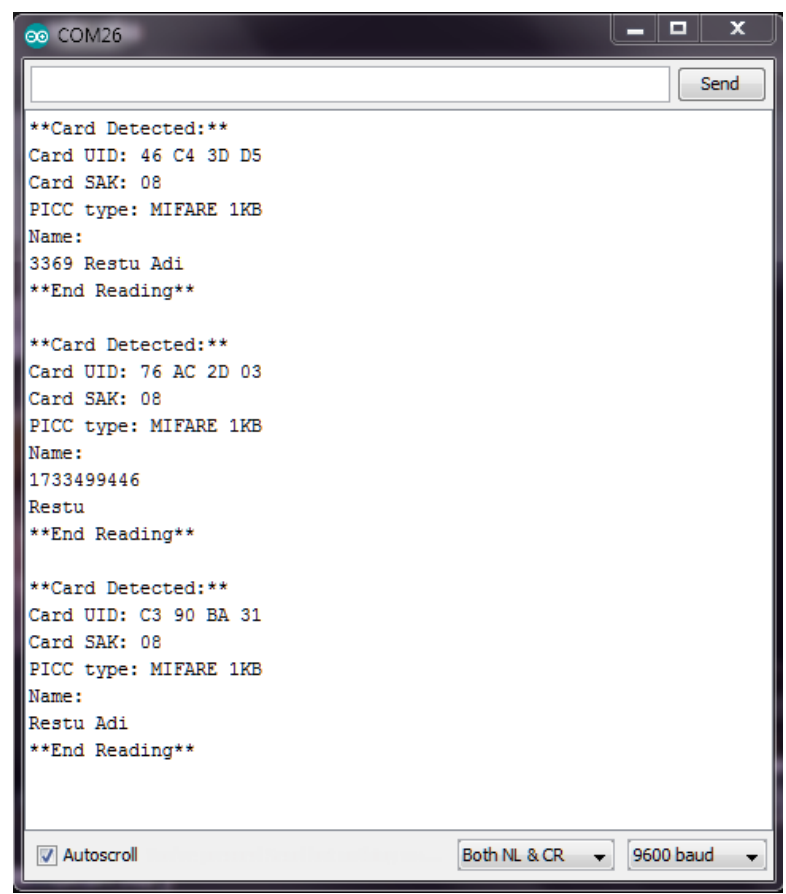

Gambar 12. Tampilan pembacaan kartu RFID pada serial monitor

Percobaan membaca data tag kartu RFID dilakukan untuk meningkatkan pemahaman pengguna trainer ini mengenai konsep-konsep teori penggunaan SPI sebagai protokol komunikasi data antara mikrokontroler dengan modul RFID MFRC522 yang menggunakan interface SPI sebagaimana materi pada mata kuliah interfacing. Pada percobaan ini pula pengguna trainer interface mikrokontroler mendapatkan pemahaman mengenai konsep komunikasi data dengan menggunakan protokol interface UART karena dalam penggunaan modul RFID pada trainer ini juga menggunakan komunikasi UART antara modul trainer dengan komputer untuk menampilkan data tag kartu RFID ke layar komputer.

\section{Analog Input Potensiometer}

Potensiometer digunakan sebagai input value yang akan ditampilkan pada percobaan interfacing LCD dan percobaan Internet of Things menggunakan aplikasi Blynk. Pada percobaan untuk menampilkan data value potensiometer ke LCD maka di dalam program untuk 
trainer ini harus didefinisikan pin 34 pada ESP32 sebagai analog input, data value yang diterima oleh ESP32 memiliki kisaran value antara 0 sampai 4096. Percobaan yang menggunakan LCD pada trainer ini harus mengikuti cara dasar interfacing LCD OLED 128x64 dan untuk menggunakan potensiometer sebagai input maka posisi toggle switch nomor 4 pada trainer ini harus pada posisi ON.

Untuk percobaan menampilkan data value potensiometer pada aplikasi Blynk, dalam memprogram trainer pastikan library Blynk sudah terinstall pada Arduino IDE serta library yang dibutuhkan oleh Blynk sudah di include pada list program beserta token yang didapat dari aplikasi Blynk pada smartphone. Informasi mengenai SSID dan password WiFi yang terhubung juga harus dideklarasikan pada list program karena pada percobaan ini alat trainer terhubung dengan jaringan WiFi. Data value dari potensiometer akan divisualisasikan dalam bentuk gauge dengan aplikasi Blynk di smartphone, mikrokontroler ESP32 pada trainer ini akan membaca analog input dari potensiometer yang terhubung pada pin 34 kemudian data dikirim melalui jaringan internet ke Blynk server untuk diolah dan data dikirim ke aplikasi Blynk pada smartphone. Pada percobaan ini dalam penggunaan trainer interface mikrokontroler akan membantu mahasiswa dalam memahami konsep dasar mengenai Internet of Things, bagaimana cara mengolah data input untuk kemudian data tersebut ditampilkan di smartphone melalui jaringan internet.

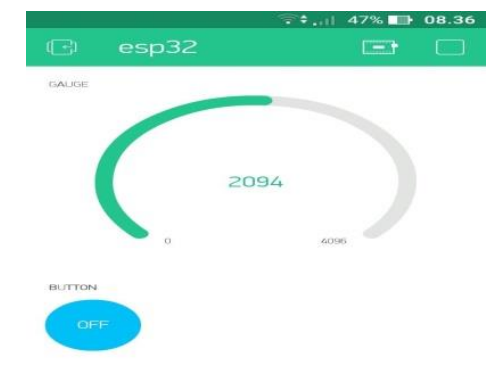

Gambar 13. Visualisasi dalam bentuk gauge di aplikasi Blynk

\section{Interfacing UART dengan Serial Monitor}

Percobaan dengan interface UART pada trainer ini sudah dapat dilakukan pada saat melakukan percobaan dengan serial monitor menggunakan modul RFID dan RTC yang sudah tertanam pada board trainer ini, namun jika pengguna trainer ingin melakukan percobaan dengan modul elektronik lainnya yang menggunakan interface UART maka trainer ini dapat ditambahkan modul dengan interface UART seperti modul SIM900 untuk melakukan percobaan dengan SMS gateway, atau dengan modul yang memiliki pin RX dan TX yang dihubungkan ke header pin ekspansi UART2 pada trainer ini. Komunikasi yang terjadi antara modul yang menggunakan interface UART dengan mikrokontroler dapat juga ditampilkan pada Serial Monitor di Arduino IDE dengan menghubungkan modul ke header pin ekspansi UART0 pada trainer ini, karena pada pin di UART0 terhubung langsung dengan chip usb to serial CP2102 yang menjadi konverter komunikasi serial dari mikrokontroler dengan USB komputer.

\section{Menghidupkan LED}

LED yang terdapat pada trainer ini dapat dihidupkan melalui aplikasi Blynk sebagai alat peraga Internet of Things, LED ini terhubung ke pin 27 mikrokontroler ESP32 sebagai output. Untuk percobaan menghidupkan LED dilakukan menggunakan aplikasi Blynk seperti pada percobaan membaca data value dari potensiometer, namun dalam percobaan ini aplikasi Blynk 
menggunakan widget button untuk menyalakan atau mematikan LED. Widget button pada aplikasi Blynk mengirimkan perintah ke Blynk Server untuk menyalakan atau mematikan LED melalui pin 27 dan perintah tersebut diterima oleh mikrokontroler ESP32 pada trainer ini melalui jaringan internet. Percobaan ini untuk membantu mahasiswa dalam memahami konsep pengontrolan output pada mikrokontroler, baik mengontrol dari komponen input maupun dari smartphone melalui jaringan internet.

\section{KESIMPULAN}

Trainer interface mikrokontroler ini dapat digunakan sebagai alat peraga atau alat praktek interface mikrokontroler baik interface SPI, I2C, dan UART. Tidak terbatas hanya untuk alat peraga untuk mempelajari interfacing saja tetapi dapat digunakan sebagai alat peraga Internet of Things karena pada trainer ini sudah terdapat komponen input berupa potensiometer yang akan memperagakan pembacaan dan pemantauan nilai analog input melalui smartphone yang terkoneksi dengan jaringan internet, dan juga terdapat komponen output berupa LED untuk memperagakan kontrol LED melalui smartphone. Selain itu terdapat beberapa pin header untuk ekspansi dari pin interface dan GPIO mikrokontroler ESP32 jika membutuhkan penggunaan komponen input output selain komponen yang sudah tertanam pada trainer. Trainer ini didesain dengan menyatukan komponen yang dibutuhkan untuk mempraktekan materi interfacing dan Internet of Things dalam satu papan sirkuit terpadu atau PCB agar dapat mengeliminasi kesalahan pada saat penghubungan antar komponen dengan mikrokontroler yang menjadi salah satu kendala dalam mempelajari interface pada mikrokontroler.

\section{SARAN}

Trainer ini tidak hanya dapat digunakan sebagai alat peraga untuk mempelajari interfacing mikrokontroler dan Internet of Things, tetapi dapat difungsikan sebagai bahan untuk mempelajari input output pada mikrokontroler, mempelajari pemrograman pada mikrokontroler, dan beberapa materi dasar sampai dengan percobaan yang lebih kompleks yang menggunakan banyak modul atau sensor. Bahasa pemrograman pada mikrokontroler ESP32 yang digunakan pada trainer ini tidak terbatas hanya bahasa $\mathrm{C}$ dengan Arduino IDE saja, namun dapat juga diprogram menggunakan bahasa python dengan micropython, Lua, dan environment bahasa pemrograman lain nya yang dapat dipelajari dengan menggunakan trainer ini.

\section{DAFTAR PUSTAKA}

[1] Sokop, S. J., Mamahit, D. J., \& Sompie, S. R. 2016. Trainer Periferal Antarmuka Berbasis Mikrokontroler Arduino Uno. Jurnal Teknik Elektro Dan Komputer, vol.5, no.3 , hal 1323.

[2] Meutia, E. D. 2015. Internet of things-keamanan dan privasi. Semin. Nas. dan Expo Tek. Elektro 2015, Banda Aceh, November 23-24.

[3] Kolban, N. 2017. Kolban's Book on ESP32. https://leanpub.com/kolban-ESP32 . diakses tgl 22 Oktober 2018.

[4] Munarso, M., \& Suryono, S., 2014. Sistem Telemetri Pemantauan Suhu Lingkungan Menggunakan Mikrokontroler dan Jaringan WIFI. Youngster physics journal, vol.3, no. 3, 
hal 249-256.

[5] Sunardi, J., \& SUTANTO, S. E. P. 2009. Rancang Bangun Antarmuka Mikrokontroler Atmega32 dengan Multimedia Card. Elektronika Instrumentasi, Jurusan Teknofisika Nuklir, STTN-BATAN, Yogyakarta.

[6] Susilo, D. 2010. 48 Jam Kupas Tuntas Mikrokontroler MCS51 \& AVR. Yogyakarta: Andi

[7] Kodali, R. K., \& Mahesh, K. S., 2016. Low cost ambient monitoring using ESP8266. 2nd International Conference on Contemporary Computing and Informatics (IC3I), Noida, Desember 14-17.

[8] N. X. P. Semiconductors. 2018. MFRC522 Standard 3V MIFARE reader datasheet. https://www.nxp.com/docs/en/data-sheet/MFRC522.pdf. diakses tgl 23 Oktober 2018.

[9] Blynk. 2018. https://www.blynk.cc/. diakses tgl 28 Oktober 2018.

[10] Somantri, Y. 2016. Pengembangan Microcontroller Embedded System untuk Training Kits. ELECTRANS, vol 14, no 1, hal 55-59.

[11] Julham, J., \& Adam, H. A. 2018. Perancangan dan Pembuatan Trainer Komunikasi RS232 Menggunakan Komputer dan Mikrokontroler. Jurnal Teknik Informatika Kaputama, vol.2, no. 1.

[12] Muchlis, F., Sulisworo, D., \& Toifur, M. 2018. Pengembangan Alat Peraga Fisika Berbasis Internet of Things untuk Praktikum Hukum Newton II. JPF: JURNAL PENDIDIKAN FISIKA, vol. 6, no. 1, hal 13-20.

[13] Luqman, R., 2017, Trainer Mikrokontroler Sebagai Media Pembelajaran Sistem Kontrol Untuk Siswa Kelas XI Program Keahlian Teknik Otomasi Industri di SMK Negeri 2 Kendal, Skripsi, Fakultas Teknik, Universitas Negeri Yogyakarta, Yogyakarta. 